\title{
Enhancing acetic acid and 5-hydroxymethyl furfural tolerance of C. saccharoperbutylacetonicum through adaptive laboratory evolution
}

\author{
Rafael F. Alves ${ }^{a, b, c}$, Ana M. Zetty-Arenas ${ }^{\text {b,c }}$, Huseyin Demirci ${ }^{\text {d,e }}$, Oscar Dias ${ }^{\text {e, Isabel Rocha }}{ }^{\text {, }}$, \\ Thiago O. Basso ${ }^{g}$, Sindelia Freitas ${ }^{\mathrm{b}, \mathrm{h}, *}$ \\ a Novozymes America Latina, Araucária, PR, Brazil \\ ${ }^{\mathrm{b}}$ Programa Integrado de Pós-Graduação em Bioenergia, Faculdade de Engenharia de Alimentos, Universidade Estadual de Campinas (UNICAMP), Campinas, SP, Brazil \\ ${ }^{\mathrm{c}}$ Laboratório Nacional de Biorrenováveis, Centro Nacional de Pesquisa em Energia e Materiais, Campinas, SP, Brazil \\ ${ }^{\mathrm{d}}$ Interdisciplinary Centre for Security, Reliability and Trust, Luxembourg \\ e Centre of Biological Engineering, University of Minho, Braga, Portugal \\ ${ }^{\mathrm{f}}$ Instituto de Tecnologia Química e Biológica, Universidade Nova de Lisboa, Oeiras, Portugal \\ ${ }^{g}$ Department of Chemical Engineering, University of São Paulo - USP, Box 61548, 05424-970, São Paulo, SP, Brazil \\ ${ }^{\mathrm{h}}$ School of Chemical Engineering, University of Campinas, (UNICAMP), Campinas, SP, Brazil
}

\section{A R T I C L E I N F O}

\section{Keywords:}

Adaptive laboratory evolution

Hemicellulosic hydrolysate

Inhibtors

Tolerance

Clostridium saccharoperbutylacetonicum

Genomic analysis

\begin{abstract}
A B S T R A C T
In this study, adaptive laboratory evolution (ALE) was applied to isolate four strains of Clostridium saccharoperbutylacetonicum able to grow in the presence of hemicellulosic hydrolysate inhibitors unsupported by the parental strain. Among them, isolate RAC-25 presented the best fermentative performance, producing $22.1 \mathrm{~g} / \mathrm{L}$ of $\mathrm{ABE}$ and $16.7 \mathrm{~g} / \mathrm{L}$ of butanol. Genome sequencing revealed a deletion in the arabinose transcriptional repressor gene $(\operatorname{araR})$ and a mutation in the anti-sigma factor I that promoted a downregulation of sigI. Gene expression analysis indicated high expression of genes related to $\mathrm{H}^{+}$-pumps (ATP synthases), proline biosynthesis (gamma phosphate reductase) and chaperonins ( $\mathrm{Grol}$ ), suggesting an integrated mechanism that is probably coordinated by the repression of sigI. Therefore, in addition to highlighting the power of ALE for selecting robust strains, our results suggest that sigI and $\operatorname{araR}$ may be interesting gene targets for increased tolerance toward inhibitor compounds relevant for lignocellulosic biofuels production.
\end{abstract}

\section{Introduction}

Butanol has emerged as a "superior biofuel" when compared to ethanol; offering advantages such as higher energy density, a less corrosive nature, higher octane number and higher hydrophobicity [1]. Additionally, butanol and its derivatives may be used in other important applications such as surface coating, plasticizing agent and as diluents; verifying the versatility and market interest of this compound [2]. Traditional butanol production has been based in the petrochemical industry; though recently, biobutanol production has received renewed interest due to its contribution to reducing the exhaustion of natural resources, environmental pollution and global warming [3]. However, biobutanol production is not economically competitive with the petrochemical-based butanol, due to the high cost of feedstock (usually molasses) and low butanol yield and productivity [3,4]. Thus, the opportunity for using low cost and abundant agro-industrial waste, which is mainly composed of lignocellulosic biomass as feedstock, opens a new chapter in the biobutanol development process [5-8].

Lignocellulosic biomass is the most abundant renewable carbon source on Earth, consisting of a composite material, primarily formed by two types of polysaccharides (cellulose and hemicellulose), and the complex aromatic compound lignin [8]. Given the recalcitrant nature of lignocellulosic biomasses, the access to whole sugars present in the plant cell walls can be carried out by two sequential hydrolysis steps; a thermochemical pretreatment to obtain the hemicellulosic hydrolysate, and an enzymatic hydrolysis of the cellulose fraction to generate the hexose-rich stream [9]. Hemicellulosic hydrolysate is a pentose rich liquor composed primarily of xylose [10] and also of inhibitory compounds formed during the pretreatment step, which can negatively affect the microbial cells and the fermentation process [11]. The presence of these toxic compounds affects cells in several ways: inhibition of cell growth by affecting glycolytic and fermentative enzymes,

\footnotetext{
* Corresponding author at: School of Chemical Engineering, University of Campinas (UNICAMP), Campinas, SP, Brazil.

E-mail address: sfazzoni@unicamp.br (S. Freitas).
} 
degradation of DNA, disruption of cell membrane and disturbance of ATP generation due to dissipation of the proton motive force [12,13]. In terms of inhibitory effects on living cells, it is well known that weak acids present in lignocellulosic-derived streams act by uncoupling energetic metabolism due to the effect of weak acids [11]. Phenolic compounds have been reported to be toxic even at low concentrations, reducing cell growth and ABE (acetone, butanol, and ethanol) production [14].

Detoxification methods such as the use of lime, peroxidases, activated charcoal, surfactant and ion-exchange resin adsorption [15-18] have been proposed to reduce the hydrolysates toxicity. Despite its effectiveness, the detoxification process involves a series of separation and purification steps that can sharply increase the overall cost of the process and limit its economic feasibility [19].

Strategies based on adaptive laboratory evolution (ALE) have been proposed as a valuable tool to enrich favorable genetic changes to obtain robust microbial cells that can withstand different inhibitor compounds. The concept of ALE or evolutionary engineering involves two approaches: repeated batch cultivation or prolonged chemostat with the presence of selective pressures to produce desired genetic variants [20]. Guo et al. obtained through continuous culture cultivation a high inhibitor tolerant mutant of C. beijerinkii; able to produce $12.9 \mathrm{~g} / \mathrm{L}$ of ABE using non-detoxified hydrolysate from corn fiber [21]. Wang et al., applying a long term adaptive evolution strategy in non-detoxified corn stover hydrolysate, obtained a robust Corynebacterium glutamicum mutant with a high tolerance to various lignocellulose derived inhibitors [22]. The evolved strain increased the conversion rate of typical lignocellulose derived inhibitors (furfural, 5-hydroxymethylfurfural, vanillin, syringaldehyde, 4-hydroxybenzaldehyde, and acetic acid) into less toxic compounds, better glucose consumption and an increase of $68.4 \%$ in glutamic acid production compared to the parental strain [22].

In this present work, we subjected $C$. saccharoperbutylacetonicum to adaptive laboratory evolution, to increase its tolerance to the main lignocellulosic derived inhibitors present in hemicellulosic hydrolysate. The evolved strains were characterized at the genomic level and compared to the wild-type strain.

\section{Material and methods}

\subsection{Bacterial strains and maintenance}

The C. saccharoperbutylacetonicum (14923) isolate was acquired from the German Collection of Microorganisms and Cell Culture (DSMZ). The strain was activated and propagated following the supplier's recommendations. Cultures were routinely maintained as a $2 \mathrm{~mL}$ suspension in glycerol $(20 \% \mathrm{w} / \mathrm{v})$ and stored at $-80^{\circ} \mathrm{C}$ until experimentation.

\subsection{Culture media preparation}

Culture medium was prepared according to Zetty et al. [23]. Strain reactivation (pre-culture) was carried out in Reinforced Clostridia Medium (RCM, Fluka, Sigma-Aldrich, Spain), at $30^{\circ} \mathrm{C}$ and inside an anaerobic chamber. For all fermentation experiments, strains were cultured in mineral medium (MM) that contained, in $\mathrm{g} / \mathrm{L}$ : xylose, 55; yeast extract, $5 ; \mathrm{KH}_{2} \mathrm{PO}_{4}, 0.75 ; \mathrm{K}_{2} \mathrm{HPO}_{4}, 0.75 ; \mathrm{NaCl}, 1 ; \mathrm{MgSO}_{4} .7 \mathrm{H}_{2} \mathrm{O}$, $0.4 ; \mathrm{MnSO}_{4} . \mathrm{H}_{2} \mathrm{O}, 0.4 ; \mathrm{FeSO}_{4} .7 \mathrm{H}_{2} \mathrm{O}, 0.01$; ammonium acetate, 4.3 and supplemented with L-asparagine, 2; para-aminobenzoic acid, 0.1; and biotin, 0.001. For adaptive laboratory evolution (ALE) experiments, cultivation was performed in MM (as described above) containing around $55 \mathrm{~g} / \mathrm{L}$ of xylose, supplemented with hemicellulosic hydrolysate $(\mathrm{HH})$ at different percentages (v/v), according to each step of the evolution protocol.

\subsection{Hemicellulosic hydrolysate production}

Hemicellulosic hydrolysate production was obtained throughout the hydrothermal pretreatment, and carried out at the pilot plant facility of the Brazilian Biorenewables National Laboratory (LNBR/CNPEM, Campinas, Brazil) following the procedure described in detail from our previous work [24]. The liquor was concentrated 5-times in a pilot evaporator at the following operating conditions: pressure: 475 16 mbar; distillate: $80^{\circ} \mathrm{C}$; temperature: $110^{\circ} \mathrm{C}-115^{\circ} \mathrm{C}$. Thereafter, the concentrated liquor was centrifuged at $9000 \mathrm{rpm}$ at $10^{\circ} \mathrm{C}$ for $20 \mathrm{~min}$. The pH was set to 6.5 using $\mathrm{NH}_{4} \mathrm{OH} 25 \%$ (w/v). Finally, the $\mathrm{HH}$ was centrifuged at $8000 \mathrm{rpm}$ for $30 \mathrm{~min}$, filter-sterilized $(0.22-\mu \mathrm{m}$ polyethersulfone top filter; Nalgene, Rochester, NY, USA) for sterilization and removal of insoluble materials that would make it difficult to measure cell growth by absorbance. The filtered hydrolysate was stored in sterile glass bottles at $-4{ }^{\circ} \mathrm{C}$ until use. Two batches of $\mathrm{HH}$ were produced and inhibitory compounds and sugars characterized and used in ALE experiments (Table 1). The same previously described protocol was used [24].

\subsection{Adaptive laboratory evolution (ALE)}

An adaptive laboratory evolution (ALE) strategy was used to obtain robust $C$. saccharoperbutylacetonicum cells able to grow in media containing inhibitors derived from $\mathrm{HH}$. For this purpose, a wild-type strain of $C$. saccharoperbutylacetonicum was submitted to serial batch cultivation in MM, supplemented with increasing concentrations of $\mathrm{HH}$ (from 20 to $40 \%$, in v/v). The initial concentration of $20 \%$ of $\mathrm{HH}(\mathrm{HH}-20)$ was based on preliminary data of wild type strain growth on medium containing different concentrations of $\mathrm{HH}(20 \%, 50 \%$ and $100 \%$, v/v) (Fig. $1 S$, Supplementary Material). All the fermentations were carried out in anaerobic chambers at $30{ }^{\circ} \mathrm{C}$ with an initial $\mathrm{pH}$ of 6.5. Firstly, the cells were cultivated in $20 \mathrm{~mL}$ of RCM the exponential phase was achieved $\left(\sim 1.5 \mathrm{OD}_{600} \mathrm{~nm}\right)$, and then $2 \mathrm{~mL}$ was transferred into $18 \mathrm{~mL}$ of $\mathrm{MM}$ supplemented with xylose containing an initial concentration of $20 \%$ $\mathrm{HH}(\mathrm{v} / \mathrm{v})$. Cells were cultivated in repetitive batch mode in this media until we observed a decrease in the doubling-time (DT). After no further decrease in this parameter, cells were transferred to another media containing a higher $\mathrm{HH}$ concentration than the previous media. For that, cells were harvested by centrifugation and resuspended in $2 \mathrm{~mL}$ of mineral media before being transferred to the new media with a higher $\mathrm{HH}$ concentration. Cells were cultivated in 25, 33 and $40 \% \mathrm{HH}(\mathrm{v} / \mathrm{v})$ along the ALE experiment. At $40 \% \mathrm{HH}$, a cultivation step without the selective pressure (no $\mathrm{HH}$ ) was performed in between cultivations containing $\mathrm{HH}$, as proposed in a previous work [25]. The doubling time (DT) was used as the main parameter to evaluate the fitness gain of the evolved population (EP) throughout the cultivations rounds. The DT was

Table 1

Concentration of inhibitors and sugars present in two different batches of hemicellulosic hydrolysate used in ALE experiments.

\begin{tabular}{lll}
\hline Compounds & 1st batch $(\mathrm{g} / \mathrm{L})$ & 2nd batch $(\mathrm{g} / \mathrm{L})$ \\
\hline HMF & $0.06 \pm 0.02$ & $0.08 \pm 0.01$ \\
Furfural & $0.01 \pm 0.01$ & $0.02 \pm 0.03$ \\
Acetic acid & $3.38 \pm 0.5$ & $4.37^{\mathrm{a}} \pm 0.8$ \\
Syringaldehyde & $0.07 \pm 0.02$ & $0.08 \pm 0.02$ \\
Glucuronic acid & $0.15 \pm 0.1$ & $0.90^{\mathrm{a}} \pm 0.3$ \\
p-coumaric acid & $0.08 \pm 0.03$ & $0.08 \pm 0.01$ \\
4Hydroxybenzoic acid & $0.01 \pm 0.02$ & $0.01 \pm 0.03$ \\
Vanillic acid & $0.009 \pm 0.003$ & $0.008 \pm 0.002$ \\
Levulinic acid & $0.18 \pm 0.09$ & $0.17 \pm 0.1$ \\
Formic acid & $0.35 \pm 0.1$ & $0.60^{\mathrm{a}} \pm 0.2$ \\
Ferulic acid & $0.16 \pm 0.09$ & $0.19 \pm 0.08$ \\
Phenylacetic acid & $0.21 \pm 0.15$ & $0.18 \pm 0.07$ \\
Vanilin & $0.08 \pm 0.02$ & $0.09 \pm 0.01$ \\
Syringic acid & $0.03 \pm 0.01$ & $0.04 \pm 0.02$ \\
Glucose & $1.51 \pm 0.8$ & $3.67 \pm 0.5$ \\
Arabinose & $12.9 \pm 1.4$ & $9.24 \pm 0.8$ \\
Xylose & $39.53 \pm 1.9$ & $47.85 \pm 1.3$ \\
Total Sugars & $53.96 \pm 1.6$ & $60.76 \pm 1.8$ \\
\hline
\end{tabular}

${ }^{\text {a }}$ Concentration significatively higher in comparison to $1^{\text {st }}$ batch. 
calculated according to the following equation:

$D T=$ Duration Culture ${ }^{*} \log (2) / \log ($ Final Concentration $)$ $-\log$ (Initial concetration)

To isolate individual colonies from the EP-40 (40\% $\mathrm{HH})$, a $2 \mathrm{~mL}$ aliquot was cultivated in $15 \mathrm{~mL}$ of RCM until the exponential phase, and subsequently plated onto solid media (RCM). The largest colonies were selected, cultivated in RCM, and stored in $20 \%$ glycerol at $-80^{\circ} \mathrm{C}$.

\subsection{Evaluation of mutants for tolerance to acetic acid and HMF}

The nine largest EP-40 colonies isolated from a solid plate (RCM) were evaluated for tolerance to acetic acid and 5-hydroxymethylfurfural (HMF). For this we carried out batch fermentations in $50 \mathrm{~mL}$ of MM containing xylose $(60 \mathrm{~g} / \mathrm{L})$, acetic acid $(5 \mathrm{~g} / \mathrm{L})$, and HMF $(0.04 \mathrm{~g} / \mathrm{L})$ to compare the growth profile and fermentative performance of the mutants and the wild type strain (WT). All fermentations were carried out in duplicate in an anaerobic chamber at $30{ }^{\circ} \mathrm{C}$. The initial $\mathrm{pH}$ was set to 4.95 and monitored off-line during fermentation using a $\mathrm{pH}$ meter (Metrohm). Cell growth was determined by measuring $\mathrm{OD}_{600} \mathrm{~nm}$ during cultivation. Samples were collected at $0,24,48,72,96,120$ and $144 \mathrm{~h}$, and centrifuged at $8000 \mathrm{rpm}$ for $10 \mathrm{~min}$ at $4^{\circ} \mathrm{C}$. The clean supernatant was transferred into $2 \mathrm{~mL}$ microtubes and stored at $-4{ }^{\circ} \mathrm{C}$ until further analysis. The concentrations of the solvents (acetone, n-butanol, and ethanol), sugars (glucose and xylose), and acids (acetic and butyric) were determined using high-performance liquid chromatography (HPLC) with a refraction index (RI) detector coupled to an Aminex HPX$87 \mathrm{H}$ column (BioRad). The mobile phase was $5 \mathrm{mM}$ sulfuric acid with a flow rate of $0.6 \mathrm{~mL} / \mathrm{min}$ at $35^{\circ} \mathrm{C}$. In addition, the inhibitors furfural and 5-hydroxymethyl-furfural were analyzed using HLPC with a specific column UV detector (Acclaim 120 - C18 $150 \times 4.8 \mathrm{~mm}$ - Thermo). The column conditions were as follows: the mobile phase was acetonitrile in water $(1: 8)$ with $1 \%$ acetic acid and a flow rate of $0.8 \mathrm{~mL} / \mathrm{min}$. All samples were previously filtered using a $0.22 \mu \mathrm{m}$ Millipore Millex-HV PVDF membrane filter. The culture growth was determined by measuring the optical density at $600 \mathrm{~nm}\left(\mathrm{OD}_{600} \mathrm{~nm}\right)$ using a UV-vis spectrophotometer (Thermo Scientific - Evolution 60S, Ann Arbor, Michigan, USA) [23].

\subsection{Genomics}

The total genomic DNA (gDNA) of four mutants selected from the 9 evaluated mutants were extracted using the Wizard Genomic DNA purification kit (Promega). The extracted gDNA was purified using PowerClean ${ }^{\circledR}$ DNA Clean-Up Kits (Mo Bio Laboratories) to ensure the sample quality. The DNA library was built by Nextera DNA sample preparation Kits (Illumina Inc., San Diego, CA, USA) and the fragmented sample was analyzed utilizing a Bioanalyzer (2100) with a 12,000 DNA assay kit (Agilent). The libraries were pooled in equimolar ratios and subsequently submitted to paired-end sequencing on MiSeq instrument with one $150 \times 150$ nt paired-end mode (Illumina platform); according to standard procedures of the Brazilian Biorenewables National Laboratory (LNBR/CNPEM, Campinas, Brazil), which resulted in about $300 \mathrm{x}$ average coverage of each sample.

\subsection{Next generation sequencing (NGS) data analysis}

The NGS pipeline consisted of the following steps: Fastq files $\rightarrow$; FastQC $\rightarrow$-; Trimmomatic $\rightarrow$; BWA-MEM/Bowtie2 $\rightarrow$; Mpileup $\rightarrow$; Varscan $\rightarrow$; SnpEff [26-33]. For mutation analysis, the default setting in Bowtie2 was used for alignment and mapping [34]. The representative genome of Clostridium saccharoperbutylacetonicum N1-4 (HMT) with taxonomy (ID) of 931276 (N1-4 (HMT) - ASM34088v1) was used as a reference genome for alignment. The results from the mapping were used to identify single nucleotide polymorphisms (SNPs), and insertions and deletions (indels) between the mutants and wild type. The results were further validated with the automatic Prokaryotic variant calling software Snippy. Genome annotation was done using Prokka and the aligned genomes and the SNP-indels were evaluated through viewing in IGV, Integrated Genome Browser [32]. Also, structural variants of the mutations were searched using the Delly software [33]. The mutations were also validated with different bioinformatics web platforms like Galaxy Melbourne and Patric. The types of mutations were classified using the SnpEff variant effect prediction software [30]. Further, the adverse of the mutations on protein sequences was predicted using Provean.

\subsection{RNA isolation}

Cell cultivation was carried out in MM containing $55 \mathrm{~g} / \mathrm{L}$ of xylose, $5 \mathrm{~g} / \mathrm{L}$ of acetic acid and $0.04 \mathrm{~g} / \mathrm{L}$ of HMF, with an initial $\mathrm{pH}$ of 6.5 . The $\mathrm{pH}$ used in this experiment was defined to allow the wild type strain to grow. For RNA isolation, $2 \mathrm{~mL}$ of culture was harvested and $4 \mathrm{~mL}$ of RNAprotect bacteria reagent (Qiagen, US) (1:2) was added immediately to stabilize and protect RNA from degradation. The material was mixed and incubated for $10 \mathrm{~min}$ at room temperature, centrifuged to obtain cell pellets, and stored at $-80^{\circ} \mathrm{C}$ for the following steps. For cell wall lysis; $200 \mu \mathrm{L}$ of TE buffer (10 mM Tris-Cl, $1 \mathrm{mM}$ EDTA, pH 8) containing lysozyme $(15 \mathrm{mg} / \mathrm{mL})$ (ThermoFicher, USA) and $20 \mu \mathrm{L}$ of proteinase $\mathrm{K}$ $(20 \mathrm{mg} / \mathrm{mL})$ were added, and cells carefully re-suspended. The material was then incubated at room temperature for $10 \mathrm{~min}$. In continuation, we added $700 \mu \mathrm{L}$ of RLT buffer (with beta-mercaptoethanol) and mixed vigorously, followed by the addition of $500 \mu \mathrm{L}$ of ethanol. The RNA was purified using an RNAeasy mini kit (Qiagen Inc, CA) according to the manufacturer's instructions. After the extraction, RNA was treated with Turbo DNAse free Kit (Invitrogen) following the manufacturer's protocol. RNA quality was analyzed using Bioanalyzer 2100 (Agilent Technologies, Santa Clara, CA, US) and the concentration was determined using NanoDrop 2000 (Thermo Scientific, Waltham, MA, USA).

\subsection{RT-qPCR analysis of selected genes}

Total RNA samples were used to synthesize the cDNA using the reagent Superscript II transcriptase reverse Kit (Invitrogen, USA) according to the manufacturer's protocol. The first round of end-point PCR was performed and the products were separated by agarose gel electrophoresis and purified with GFX ${ }^{\mathrm{TM}}$ PCR DNA and Gel Band Purification kit (GE Healthcare, US). The amplicons were subjected to a 10-fold serial dilution (from $10^{-1}$ to $10^{-8}$ ) and used to construct a standard curve. RTqPCR reactions were performed according to Borin et al. along with the five best points of the standard curve and the cDNA samples from the experiments (see above), to keep the same conditions for standards and experimental samples (relative standard curve method) [35]. Primer sequences and genes analyzed are provided in Table 2. All RT-qPCR reactions were carried out in ViiA 7 Real-Time PCR system (Applied Biosystems, Life Technologies) using the following amplification conditions: activation for $10 \mathrm{~min}$ at $95^{\circ} \mathrm{C}$ followed by 40 cycles of denaturation $\left(15 \mathrm{~s}\right.$ at $\left.95^{\circ} \mathrm{C}\right)$, annealing and extension $\left(1 \mathrm{~min}\right.$ at $\left.60^{\circ} \mathrm{C}\right)$. Data normalization was performed using quantification obtained from the housekeeping genes 1 and 2 (Table 2), and all reactions were conducted in triplicate. Statistical significance of the results was determined using analysis of variance ANOVA (Tukey's test), with a significance level of $95 \%(\mathrm{p}<0.05)$. Analyses were performe using the GraphPrism 7.0 (GraphPad Software, San Diego, CA, USA).

\subsection{Scanning electron microscopy}

Morphology of bacterial cells (mutants and wild type) were analyzed using scanning electron microscopy (SEM). All strains were cultivated in individual batches on RCM in 15-mL shake flasks without agitation. All fermentations were carried out at $30^{\circ} \mathrm{C}$ inside an anaerobic chamber. 
Table 2

Primers used for RT-qPCR analyses of gene expression in wild type and mutants (RAC-21 and RAC-25).

\begin{tabular}{|c|c|c|c|}
\hline Gene name & Locus tag & Function & Primers 5'-3'(forward, reverse) \\
\hline$r p s L$ & & Interacts with and stabilizes bases of the $16 \mathrm{~S}$ rRNA that are involved in tRNA selection in the A site & GAGGTTGCTGAGAGGATTAATGC \\
\hline $\begin{array}{l}\text { Housekeeping } \\
1\end{array}$ & CSPA_RS00900 & $\begin{array}{l}\text { and with the mRNA backbone. } 30 \text { S ribosomal protein S12; With S4 and S5 plays an important role } \\
\text { in translational accuracy }\end{array}$ & GATTCTACCTTTGGCCTTGGAA \\
\hline$r p s B$ & & & GAAGCAGGTGTACATTTCGGAC \\
\hline $\begin{array}{l}\text { Housekeeping } \\
2\end{array}$ & CSPA_RS06500 & Ribosomal protein S2 belongs to the universal ribosomal protein uS2 family. & TACCTTCATCAGCTACTTGC \\
\hline sigI & CSPA_RS16265 & $\begin{array}{l}\text { Sigma factors are initiation factors that promote the attachment of RNA polymerase to specific } \\
\text { initiation sites and are then released. }\end{array}$ & $\begin{array}{l}\text { CTGAGATCGGTTCGTTCGGT } \\
\text { GCTACTATTCTTGTAATAGGCAATCTC }\end{array}$ \\
\hline proA & CSPA_RS00190 & $\begin{array}{l}\text { Catalyzes the NADPH-dependent reduction of L-glutamate 5-phosphate into L-glutamate 5-semi- } \\
\text { aldehyde and phosphate. }\end{array}$ & $\begin{array}{l}\text { AGTAAGCATGGGGCAAAATG } \\
\text { ATTCGTGCAGCTTCTAGATC }\end{array}$ \\
\hline$a t p D$ & CSPA_RS03060 & Produces ATP from ADP in the presence of a proton gradient across the membrane. & $\begin{array}{l}\text { TGAGGTTTCAGCGTTACTTGGA } \\
\text { AGTCATCGGCAGGAACATATACTG }\end{array}$ \\
\hline groL & CSPA_RS02180 & $\begin{array}{l}\text { Prevents misfolding and promotes the refolding and proper assembly of unfolded polypeptides } \\
\text { generated under stress conditions. }\end{array}$ & $\begin{array}{l}\text { GGAAAAAGTAGGAAATGAAGGCG } \\
\text { GCTTCTCCTTCAATGTCTTCAGC }\end{array}$ \\
\hline
\end{tabular}

Samples were taken at $24 \mathrm{~h}$ of cultivation and prepared according to the protocol established by Grassi et al. [36]. Samples were first filtered through $0.22 \mu \mathrm{m}$ filters and then fixed for one hour (1 h) using $2.5 \%$ glutaraldehyde in $0.1 \%$ phosphate buffer ( $\mathrm{pH} 7.4$ ), followed by a washing step with $0.1 \mathrm{M}$ phosphate buffer (pH 7.4) for $15 \mathrm{~min}$. Subsequently, the samples were dehydrated in a graded ethanol series $(30 \%$ until $100 \%$ ) and subjected to critical point drying followed by sputter-coating. Finally, samples were analyzed in a scanning electron microscope JSM 5800 L V (Jeol).

\section{Results and discussion}

3.1. Adaptive Laboratory Evolution of C. saccharoperbutylacetonicum in the presence of hemicellulosic hydrolysate $(\mathrm{HH})$

ALE was carried out in batch cultivations with an initial concentration of $20 \% \mathrm{HH}(\mathrm{HH}-20)$ diluted in MM. This initial concentration was based on preliminary growth profile of the wild type strain on medium containing different concentrations of $\mathrm{HH}(20 \%, 50 \%$ and $100 \%, \mathrm{v} / \mathrm{v})$ (Fig. 1S, Supplementary Material). The subsequent cultivations at increased concentrations of $\mathrm{HH}$ were applied when a reduction or a stabilization of the doubling time (DT) was observed along with the cultivation rounds. We then progressively increased the $\mathrm{HH}$ fraction in the MM. The progression of ALE for C. saccharoperbutylacetonicum under increasing concentrations of $\mathrm{HH}(25 \%, 33 \%$ and $40 \%, \mathrm{v} / \mathrm{v})$ is depicted in Fig. 1.

At $\mathrm{HH}-20$ cultivations, five repetitive batch cultivations (rounds) were performed, encompassing 13 generations. In this first step, cells were able to grow at a fairly constant DT over the five rounds, suggesting

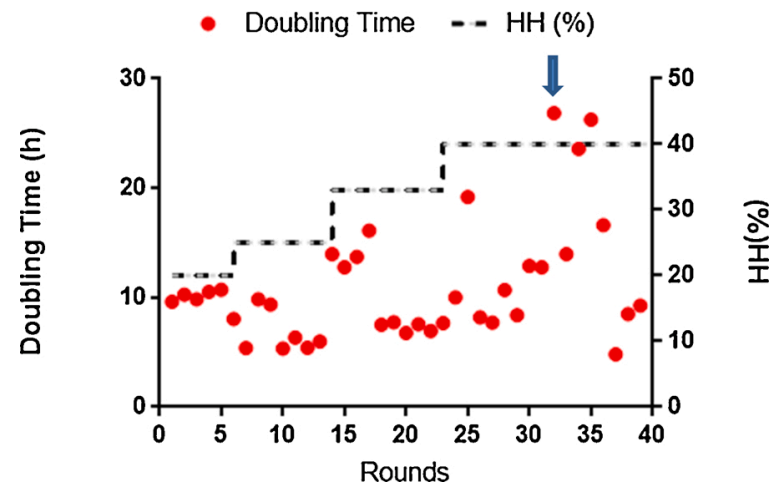

Fig. 1. Progression of adaptive laboratory evolution (ALE) of C. saccharoperbutylacetonicum in terms of doubling times of the average bacterial population, submitted to repetitive batch cultivations (rounds) under increasing concentrations of hemicellulosic hydrolysate (HH). The arrow in graph indicates the second batch of HH used in media composition for ALE. that at $20 \%$ concentration (HH-20) the inhibitor titers did not severely impact microbial cells. The evolution experiment was continued by changing to a medium containing $25 \% \mathrm{HH}(\mathrm{HH}-25)$, starting with the evolved population (EP-20). Under this condition, eight rounds were performed for a total of 27 generations. The DT progressively decreased during the cultivations, with a reduction of $30 \%$ of DT in the last four rounds, in comparison to the first four rounds. Subsequently, we continued the evolution protocol in the presence of $\mathrm{HH}-33$, starting with EP previously obtained (EP-25). After nine rounds and 22 generations in this condition, we were able to obtain an evolved population (EP-33) with a reduction of $48 \%$ in DT in the last five rounds compared to the first four rounds. In the last step of ALE, we challenged the EP-33 with $\mathrm{HH}-40$. Cells were submitted to 17 rounds of cultivation, comprising of 66 generations under this condition. The results indicate that until round nine, the DT was practically unchanged. However from round 10 to 14, this parameter increased consistently. This fact can be explained by fcat that the $\mathrm{HH}$ used in these experiments (batch 2) presented higher concentration of inhibitors compared to the first batch, and consequently appeared to be more toxic to the cells at the same concentration (HH-40) (Table 1). To facilitate data analyses, we can consider cultivations from round one to nine performed with the first batch of $\mathrm{HH}$ as separate; and from round ten to seventeen as another that utilized the higher inhibitor $\mathrm{HH}$ batch. In this case, we can divide the ALE with HH-40 into two parts. In the first, cells were evolved over 24 generations and a significant improvement in DT or final OD was not observed. In the second, we observed an increase of DT in the initial rounds due to the higher inhibitor concentration of the new HH batch, followed by a substantial decrease in DT. After approximately 130 generations, the adopted ALE strategy resulted in an evolved population (EP-40) with an improved fitness in HH supplemented media; with a $26 \%$ reduction in DT, in comparison to the cultivations with $\mathrm{HH}-20$ and $\mathrm{HH}-40$ (last three rounds). Finally, in order to obtain isolates from this EP-40, cells were plated onto solid RCM medium, and large colonies were selected and stored (Fig. 2).

\subsection{Evaluation of evolved isolates towards acetic acid and HMF}

The isolation of single EP-40 colonies from a solid plate (RCM) resulted in 9 colonies (mutants); to be evaluated for tolerance to acetic acid and HMF, previously identified (Table 1S, Table 2S and Fig. 2S, Supplementary Material) as the inhibitors that most negatively impact C. saccharoperbutylacetonicum growth. The isolates from the ALE experiment (EP-40 isolates) were evaluated in MM containing acetic acid and HMF. The concentration of inhibitors $(5 \mathrm{~g} / \mathrm{L}$ of acetic acid and $0.04 \mathrm{~g} / \mathrm{L}$ of HMF) used in this work were higher than those present in the medium with $\mathrm{HH}-40$. Cultivation under the presence of acetic acid and HMF showed that not all isolated mutants were able to grow under such conditions (Fig. 3).

Only four isolates (named RAC-2, RAC-8, RAC-21, and RAC-25) were 


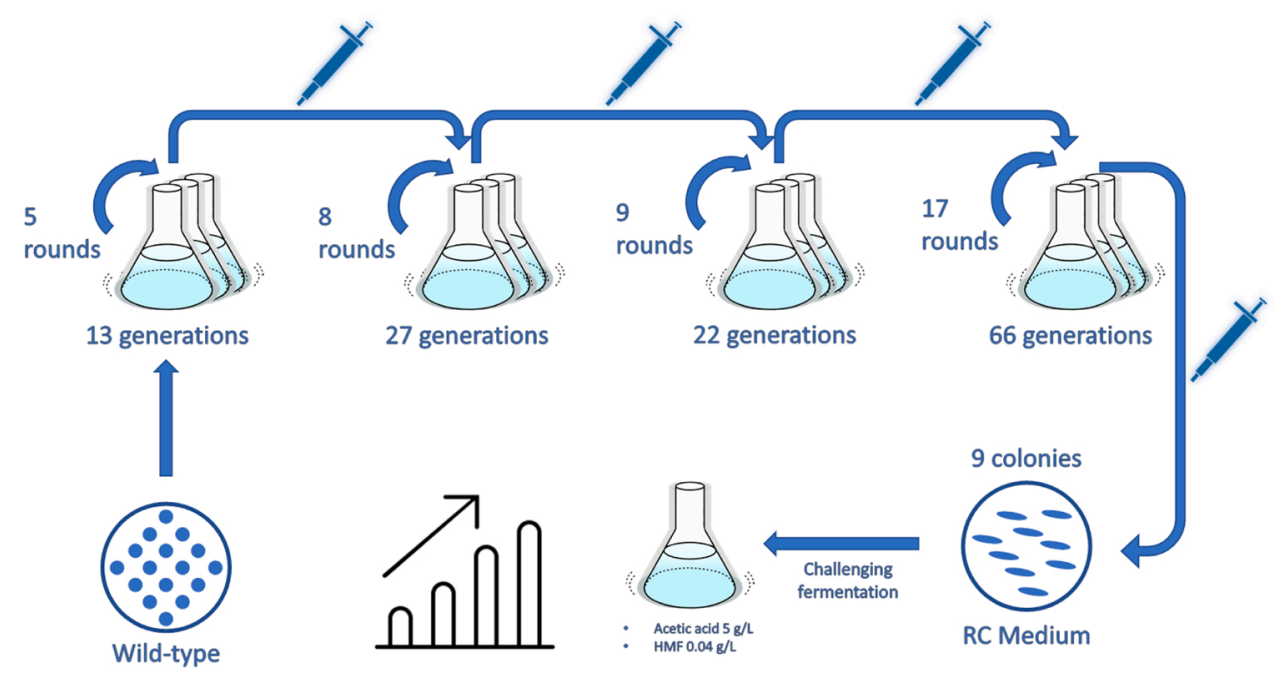

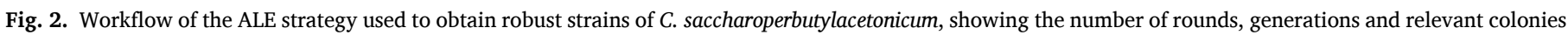
picked for further steps.

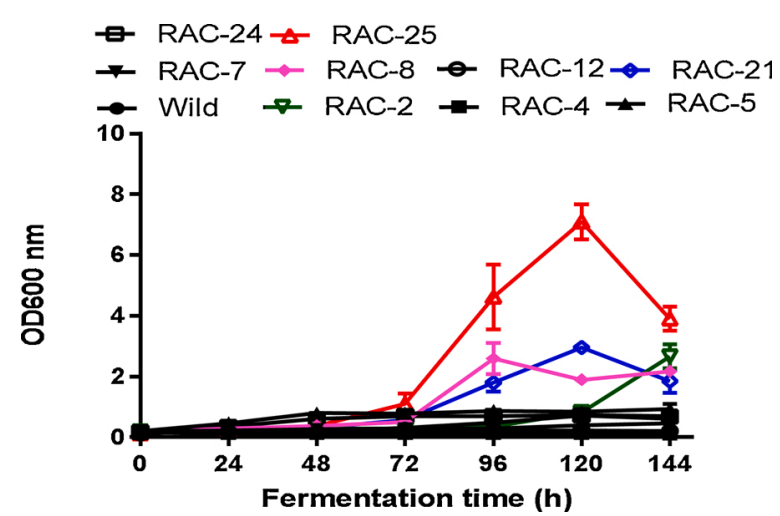

Fig. 3. Comparison of microbial growth of nine mutants (RAC-2, RAC-4, RAC5, RAC-7, RAC-8, RAC-12, RAC- 21, RAC-24 and RAC-25) and wild type in MM supplemented with acetic acid (5 g/L) and HMF $(0.04 \mathrm{~g} / \mathrm{L})$ during $144 \mathrm{~h}$ of batch fermentation. The experiments were carried out in duplicate.

able to reach an OD higher than 1.0. On the other hand, the wild type strain was not able to grow at all, confirming that ALE under HH promoted improved resistance toward acetic acid and HMF. Moreover, mutant RAC-25 revealed the best growth among the isolates; reaching a maximum $\mathrm{OD}_{600} \mathrm{~nm}$ of 7 in $120 \mathrm{~h}$ of fermentation. All mutants (RAC-2, RAC-8, RAC-21, and RAC- 25) were able to produce solvents despite the low acid production and the stressful environment imposed by the presence of acetic acid and HMF (Fig. 4 and Table 3S, Supplementary Material).

It is well known that solventogenic Clostridia spp. have a typically biphasic metabolism, where during the first phase (acidogenic) acids are produced (acetic acid and butyric acid) concomitantly with microbial growth. Consequently, due to the low $\mathrm{pH}$ promoted by acid production, cells switch their metabolism to the next phase (solventogenic); in which the acids (acetic and butyric) are re-assimilated into solvents (acetone, butanol, and ethanol). Butanol production via this route is known as the "cold channel" [37]. Another alternative pathway is when butanol is directly produced from acetyl-coenzyme A (CoA) through butyryl-CoA, and is known as the "hot channel" [37]. In literature, it is reported that $15.1 \mathrm{~g} / \mathrm{L}$ is the maximum titer of butanol produced by C. saccharoperbutylacetonicum under normal conditions without inhibitors (Fuel, 2017). The direct butanol forming hot channel has been described as playing a pivotal role in enhanced butanol production in comparision to cold channel [37]. Shinto et al. developed a model that showed C. saccharoperbutylacetonicum N1-4 has a robust metabolic network in the acid and solvent producing pathways [38]. The results obtained in our work suggest that the mutants (RAC-2, RAC-8, RAC-21, and RAC-25) with high tolerance to inhibitors (acetic acid and HMF) tend to preferentially produce butanol from the "hot channel" instead of the "cold channel", since small amount of acids (acetic and butyric) were produced during fermentation (Fig. 4). Our results are consistent with results obtained by Jin et al., where they observed a down regulation of the metabolic flux towards the acid formation branch ("cold channel"), and an up-regulation of the metabolic flux toward the ABE formation branches ("hot channel"); and consequently improved C. acetobutylicum fermentation of a non-detoxified wheat straw hydrolysate supplemented with sodium sulfite [39].

Mutant RAC-25 displayed a remarkable fermentative performance in the presence of inhibtors, consuming $84 \%$ of the sugars and producing $22.1 \mathrm{~g} / \mathrm{L}$ of $\mathrm{ABE}\left(\mathrm{Y}_{\mathrm{ABE} / \mathrm{S}}=0.42 \mathrm{~g} / \mathrm{g}\right.$ ) (Table $3 S$, supplementary material). Moreover, RAC-25 was able to achieve a cell density $\left(\mathrm{OD}_{600} \mathrm{~nm}\right.$ of 7.0$)$ similar to that observed for the wild type strain $\left(\mathrm{OD}_{600} \mathrm{~nm}\right.$ of 9.14$)$ in media without inhibitors (data not shown). Regarding butanol titer, mutant RAC-25 was able to produce $16.6 \mathrm{~g} / \mathrm{L}$ of butanol $\left(\mathrm{Y}_{\text {BUT } / \mathrm{S}}=0.32 \mathrm{~g} /\right.$ $\mathrm{g}$ ); which is, to the best of our knowledge, the highest titer reported for batch cultures in a medium with a high concentration of acetic acid. In literature, $15.1 \mathrm{~g} / \mathrm{L}$ is reported as the maximum titer of butanol produced by C. saccharoperbutylacetonicum under normal condition without inhibitors [14].

The remaining mutants (RAC-2, RAC-8, and RAC-21) were able to consume around $50 \%$ of the sugars and produce similar titers of butanol and $\mathrm{ABE}$ solvents. Nevertheless, mutant RAC-2 achieved the highest butanol $\left(\mathrm{Y}_{\mathrm{BUT} / \mathrm{S}}=0.34 \mathrm{~g} / \mathrm{g}\right)$ and $\mathrm{ABE}$ yield $\left(\mathrm{Y}_{\mathrm{ABE} / \mathrm{S}}=0.50 \mathrm{~g} / \mathrm{g}\right)$ despite consuming less sugar (46.7 \%) than the other mutants. Normally, both acetic and butyric acids are produced together with ATP generation in the acidogenic phase. These acids are then taken up for the production of butanol and ethanol, during the solventogenic phase, thus enabling an electron sink [37]. Another explanation for the high conversion yield observed in acetate containing media is the possible increased conversion of acetate to butanol to reduce its toxicity. Thus, a significant fraction of the solvents produced by the mutant RAC- 2 can be formed from acetate. It is important to mention that an in-depth investigation, using metabolic modelling, for example, could be conducted to test this hypothesis, although no metabolic model for C. saccharoperbutylacetonicum is available until now.

In summary, our results revealed that the amount of butanol secreted by the mutant RAC-25 $(16.6 \mathrm{~g} / \mathrm{L})$ in a batch fermentation exceeds previously reported limits for butanol tolerance for this bacteria [23]; which leads us to conclude that the adaptive evolution brought genetic 
A

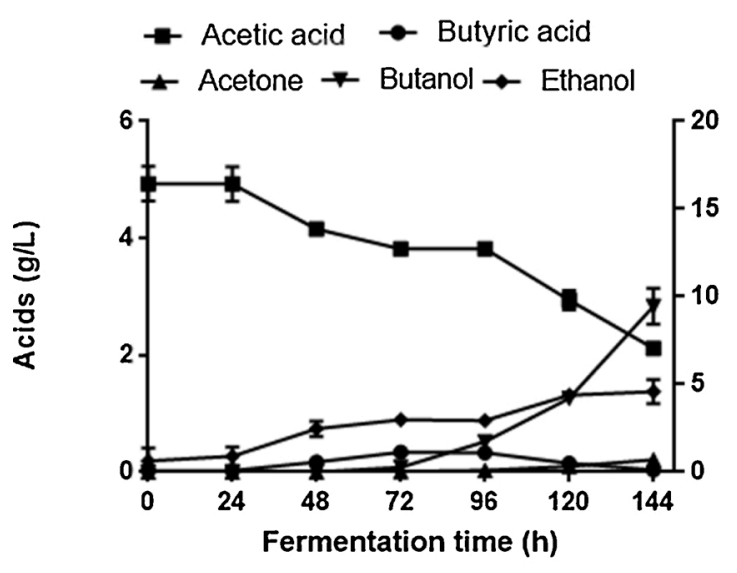

C

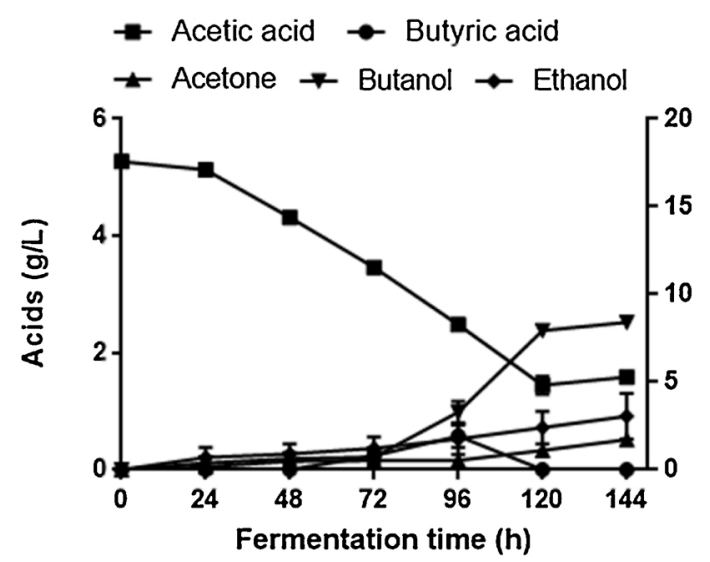

B

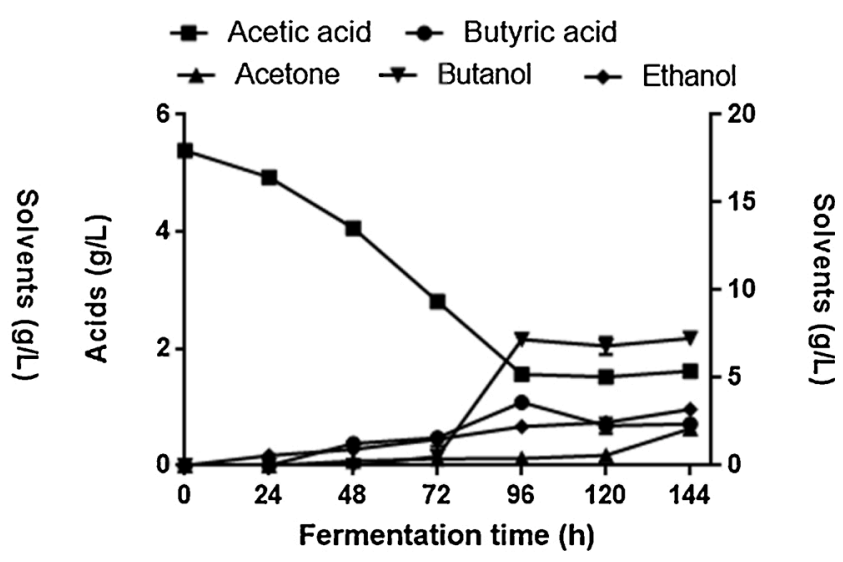

D

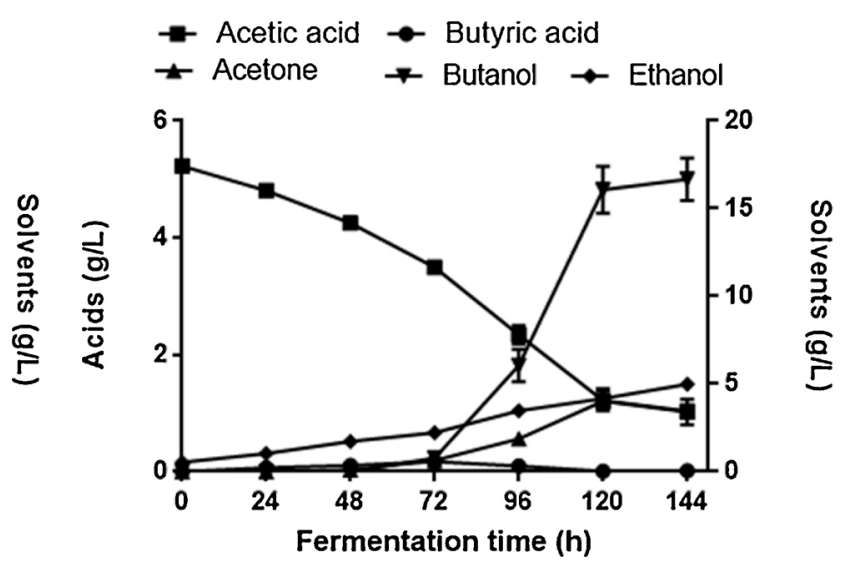

Fig. 4. Profile of acid and solvent production of mutants RAC-2 (A), RAC-8 (B), RAC- 21 (C) and RAC-25 (D) during fermentation in mineral media containing acetic acid $(5 \mathrm{~g} / \mathrm{L})$ and HMF $(0.04 \mathrm{~g} / \mathrm{L})$.

mutations that not only promoted tolerance to acetic acid and HMF but also increased the $\mathrm{ABE}$ production.

\subsection{Genomic analysis of the evolved isolates}

The results presented in the previous sections strongly support that the ALE strategy has generated mutants with higher growth capabilities as well as the best solvent production in the presence of inhibitors (acetic acid and HMF) compared to the parental strain. To provide more information about the the different phenotype obtained throught ALE, we sequenced the genome of mutants (RAC-2, RAC-8, RAC-21, and RAC25) and compared them to the wild type. Mutations were identified by whole-genome re-sequencing and each genome was compared with the parental strain (ID129676) in Genbank (NCBI). The results of the alignment process for each strain generated a mean mapping ratio of about $99.98 \%$ with high genome coverage (a least mean value of 123.7x) for each strain, which implied excellent quality for variant calling (Table 4S, Supplementary Material). The obtained mutations,

Table 3

Summary of mutations found in evolved strains.

\begin{tabular}{|c|c|c|c|c|c|}
\hline Strain & Mutation & Type & Position & Gene & Function \\
\hline \multirow{4}{*}{ RAC-2 } & Stop gained & SNP & Glu428* & CSPA_RS22950 & Catalyzes the phosphorylation on incoming sugar substrates \\
\hline & Deletion & Deletion & F171fs & CSPA_RS16265 & Promote the attachment of RNA polymerase to specific initiation sites \\
\hline & Missense & SNP & Leu3Ser & CSPA_RS14550 & Uncharacterized protein \\
\hline & Missense & SNP & Ile61 Met & CSPA_RS17655 & Oxidoreductase activity \\
\hline \multirow{5}{*}{ RAC-8 } & Stop gained & SNP & Glu428* & CSPA_RS22950 & Catalyzes the phosphorylation on incoming sugar substrate \\
\hline & Deletion & Deletion & F171fs & CSPA_RS16265 & Promote the attachment of RNA polymerase to specific initiation sites \\
\hline & Missense & SNP & Leu3Ser & CSPA_RS14550 & Uncharacterized protein \\
\hline & Missense & SNP & Glu210Gly & CSPA_RS14135 & Probably involved in glucitol uptake (carbohydrate transport) \\
\hline & Missense & SNP & Gly30Ser & CSPA_RS00360 & Protein involved in the pathway lipoprotein biosynthesis \\
\hline \multirow{5}{*}{ RAC-21 } & Stop gained & SNP & Glu428* & CSPA_RS22950 & Catalyzes the phosphorylation on incoming sugar substrates \\
\hline & Deletion & Deletion & F171fs & CSPA_RS16265 & Promote the attachment of RNA polymerase to specific initiation sites \\
\hline & Missense & SNP & Leu3Ser & CSPA_RS14550 & Uncharacterized protein \\
\hline & Missense & SNP & Glu210Gly & CSPA_RS14135 & Probably involved in glucitol uptake (carbohydrate transport) \\
\hline & Missense & SNP & Gly30Ser & CSPA_RS00360 & Protein involved in the pathway lipoprotein biosynthesis \\
\hline \multirow{3}{*}{ RAC-25 } & Stop gained & SNP & Ser25* & CSPA_RS22795 & Involved in the regulation of arabinose metabolism (repressor) \\
\hline & Missense & SNP & Leu23Trp & CSPA_RS19575 & Uncharacterized protein \\
\hline & Missense & Complex & Lys271fs & CSPA_RS16260 & Anti-sigma factor for Sigl regulation through direct interaction \\
\hline
\end{tabular}


related genes, and functional information are summarized in Table 3.

Results indicate that some of the mutations were shared among the isolated mutants, while others were exclusively present in one of the mutants. To facilitate data analysis, we arranged the mutants into two groups: Mutants RAC-2, RAC-8 and RAC-21 who shared mutations in similar genes (CSPA_RS22950, CSPA_RS14550, CSPA_RS16265), while mutant RAC-25 presented mutations in different genes (CSPA_RS22795, CSPA_RS19575 and CSPA_RS16260).

The ability of biological systems to respond to various environmental or nutritional changes is directly correlated to biochemical and genetic networks [40]. In this sense, several genes are necessary for this complex process. Among them, we can mention the recognition by RNA polymerase associated with alternative sigma factors. We noted that two of the mutations found were present in genes related to sigma factors. Mutants RAC-2, RAC- 8 and RAC-21 showed a deletion in gene CSPA_RS16265, which produces the RNA polymerase sigma factor I (sig I). Sigma factors are normally responsible for producing a multi-domain subunit of bacterial RNA polymerase, and therefore it plays an important role in transcriptional initiation [41]. Beyond that, this gene (sigI) is also involved in the regulation of cell wall metabolism in response to heat stress in Bacillus [42]. So far, this is the first work revealing a possible role of this specific sigma factor (sigI) in solventogenic Clostridium spp., since most of them have been reported in Bacillus spp. [43-45]. On the other hand, mutant RAC-25 showed a mutation (missense type) in the CSPA_RS16260 gene which produces the anti-sigma factor responsible for the down-regulation of sigma factor I (sigI). Many works have described the involvement of transcriptional factors in stressful conditions, as well as strategies to enhance tolerance to many inhibitor compounds by manipulating these transcriptional factors [46-49]. Considering the mutations found in all the mutants, it was expected that RAC-2/RAC-8/RAC-21 showed a down regulation of sigI, since they presented a deletion in the gene responsible for sigI expression. On the other hand, regarding the mutant RAC-25, we expected a high expression of sigI due to a mutation in the anti-sigI gene, responsible for the sigI gene regulation.

Furthermore, we have also identified mutations in genes involved in membrane transport and the transcriptional regulators of carbohydrates. The mutant RAC-25 presented a mutation (stop gained) in the CSPA_RS22795 gene that belongs to the GntR transcriptional regulator family; which is a large group of proteins present in diverse bacteria and regulates various biological processes. This gene (CSPA_RS22795), named $\operatorname{araR}$ is responsible for the repression of genes related to arabinose metabolism and the pentose phosphate pathway in Clostridium spp [50]. In Gram positive organisms the arabinose operon is negatively regulated by araR, binding to operator regions of the arabinose operon in the absence of arabinose. On the other hand, in the presence of arabinose the sugars bind to araR promoting conformational changes and preventing its binding to DNA [51]. It has been reported that concomitant downregulation of XylR and/or araR may improve mixed-sugar utilization in solventogenic Clostridium species [52]. In a study conducted by Zhang et al. (2012), the researchers used a comparative genomic approach to identify AraR-binding DNA motifs and reconstruct AraR regulons in nine different Clostridium spp. The results obtained indicated that the expression of genes related to the pentose phosphate pathway, like $t k t$ (CAC1348), tal (CAC1347) and ptk (CAC1343), were up-regulated in the absence of arabinose in the mutant strain (araR inactivation) in comparison to wild type [50]. Their study corroborates with our results obtained from mutant RAC-25, which indicate that the mutation in gene araR could de-repress genes involved in xylose metabolism and improve sugar uptake (Fig. 3, Table 3S and Fig. 3S, Supplementary Material).

It has been shown that the inactivation of the XylR transcriptional repressor has been associated with increased utilization of xylose as the main substrate in C. beijerinkii and C. acetobutylicum [53,54]. A study conducted by Xiao et al. (2017) evaluated a point mutation in DNA dependent RNA polymerase (ropB) regarding osmotolerance and succinic acid production in $E$. coli. The authors showed that the mutation rendered E. coli resistant to osmotic stress, probably due to improved cell growth and viability via enhanced sugar uptake under stress conditions, and activated a potential "pre-defense" mechanism under non-stressed conditions [55].

Another mutation (stop gained) shared by mutants RAC-2, RAC-8 and RAC-21 is present in gene CSPA_RS22950 $(g l c B)$, which encodes the glucose specific EIICBA protein component of the PTS (phosphotransferase system) system. The PTS system carries out both catalytic and regulatory functions in microbial cells. It plays an important role in transport mechanism of carbohydrate substrate, catalyzing both the accumulation and chemical conversion (phosphorylation) [56]. Since it has an important role in sugar uptake, we expected the mutation in CSPA_RS22950 (stop gained) would impact negatively the microbial growth and butanol production. Indeed this mutation showed a negative effect on microbial cells, impacting the substrate uptake and energy metabolism in MM with (Table 3) and without inhibitors (Fig. 3S, Supplementary Material). As mentionated before, this could be a strategy of cells, similar to catabolic repression, to consume the acetate present in media to avoid the deleterious effect caused by this acid at high concentrations. However, it is important to point out that there is a lack of knowledge describing a possible strategy to overcome hostile acidic conditions. Therefore, additional studies are required to deeply investigate this hypothesis of carbon catabolite repression (CCR) to promote acetate consumption.

\subsection{RT-qPCR analysis of selected genes}

Based on the results presented above, we hypothesized that in the first group (RAC-2, RAC-8 and RAC-21) sigma factor expression should be decreased, whereas in the second group (RAC-25) its expression should be increased when compared to the parental strain. To verify our hypotheses, we evaluated the expression level of sigma factor I and other genes related to stress conditions in two mutants from each group (RAC21 and RAC-25), in comparison to the wild type strain. The genes investigated were: sigI (CSPA_RS16265), proA (CSPA_RS00190), groL (CSPA_RS02180) and atpD (CSPA_RS03060) (Fig. 5).

The results indicated that the expression of sigI was significantly different $(\mathrm{p}<0.005)$ in the mutants studied (RAC-21 and RAC-25) compared to the wild type (WT) in all tested cultivation times (15, 24 and $48 \mathrm{~h}$ ) (Fig. 5). Moreover, the mutant RAC-21 did not express the sigI, as expected, due to the deletion of this gene, confirming the results obtained in the genome sequencing. On the other hand, the mutant RAC25 surprisingly revealed a lower expression of the sigI gene in comparison to the wild type (WT). Down-regulation of sigI might be explained by the fact that the mutation in the anti-sigma factor can affect the mechanism responsible for "switching-off" the sig I protein; promoting a phenotype similar to the other mutants (RAC-2, RAC-8 and RAC-21). In the work performed by Minty et al. (2010), experimental evolution was applied to obtain $E$. coli mutants tolerant to exogenous isobutanol. Their results showed that many isobutanol tolerant strains presented a reduced activity in RpoS (sigma factor), probably related to a mutation in $h f q$ or acrAB. They concluded that the mechanism for adaptation to isobutanol was based on cell envelope remodeling and stress response attenuation [57]. In another work, Riordan et al. showed that the inactivation of alternative sigma factor $54(r p o N)$ affected the expression of stress resistance genes, most notably the gad genes required for GDAR (glutame-dependent acid resistance); promoting an increase in acid resistance in the mutant strain [58]. Our results with sigI suggest that the low expression of sigI can promote an improvement in tolerance of C. saccharoperbutylacetoncium towards acetic acid and HMF. However, it is important to note that until now, no other work has described which genes are regulated by sigI (CSPA_RS16265) in solventogenic Clostridium spp.

Beyond sigI, we also evaluated the expression of other genes involved in stressful conditions (proA, atpD and grol). The expression of the 
sigl
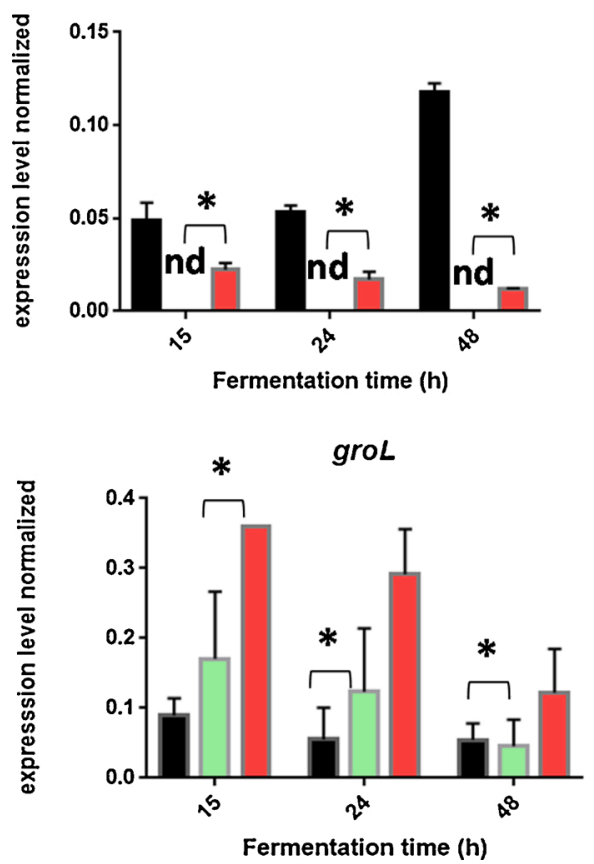

proA

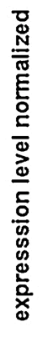
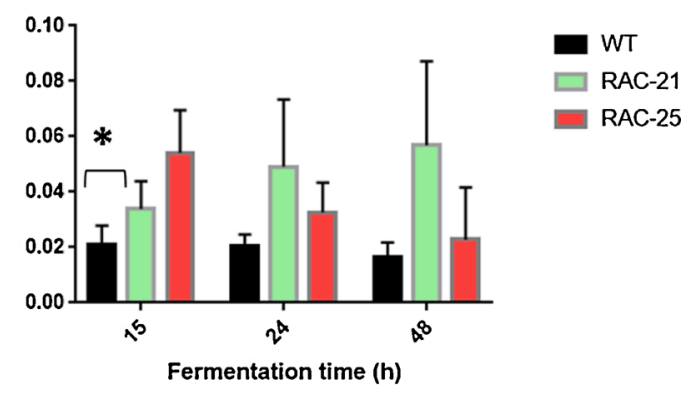

$\operatorname{atpD}$
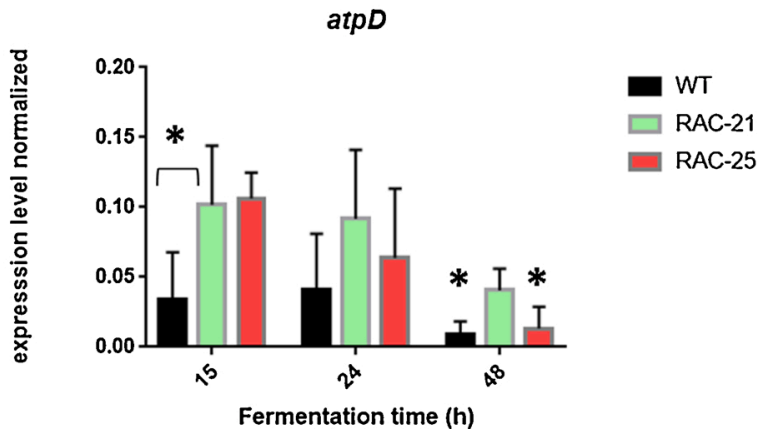

Fig. 5. Real-time PCR of genes involved in stress conditions for wild type (WT) and mutants RAC-21 and RC-25 obtained by ALE. Genes investigated are: sigI (CSPA_RS16265), proA (CSPA_RS00190), groL (CSPA_RS02180) and atpD (CSPA_RS03060). ND: not detected.

gamma-glutamyl phosphate reductase (proA) gene, that is involved in $\mathrm{L}^{-}$ proline biosynthesis [59], was also evaluated (Fig. 5). The results indicated a higher expression level of proA throughout cultivation in both mutants (RAC-21 and RAC-25) in comparison to the wild type. However, statistical analysis showed only differences between RAC-25 and WT at $15 \mathrm{~h}$ of cultivation. The results suggest that high expression of proA could be related to the improved tolerance to lignocellulosic inhibitors, in this case to acetic acid and HMF. Our data corroborates with results obtained by Liao et al. (2018), who showed that overexpression of some genes in (proA, proB, and proC) C. acetobutylicum to enhance proline biosynthesis promoted an excellent ability to withstand inhibitors (formic acid, ferulic acid, p-coumaric acid and syringaldehyde); and efficiently fermented undetoxified hydrolysates from different raw materials (soybean straw, rice straw, and corn straw) [60].

The grol gene which produces the $60 \mathrm{kDa}$ chaperonin was also evaluated. This gene is responsible for preventing misfolding and promoting the refolding; and proper assembly of unfolded polypeptides generated under stress conditions. Our results indicate higher expression of grol in mutants (RAC-21 and RAC-25) at 15 and $24 \mathrm{~h}$ of cultivation (Fig. 5). Statistical analysis only showed significant differences between mutants and the wild type at $15 \mathrm{~h}$, and between mutant RAC- 25 and WT at 24 and $48 \mathrm{~h}$. In a study conducted by Tomas et al. (2003), it was observed that the overexpression of the groELS gene in C. acetobutylicum promoted an increase of butanol tolerance and solvent production [61]. In another study the researchers constructed a recombinant strain of C. beijerinkiii NCBI 8052 to overexpress groES and groEL and observed a higher solvent production, even under ferulic acid stressed conditions; providing a good candidate strain for biomass hydrolysate fermentation [62].

Finally, to investigate the acid tolerance of mutants, we evaluated the expression of $\mathrm{H}^{+}$ATPase (ATP synthase); since the response to organic acids, cells have demonstrated an increase in membrane $\mathrm{H}^{+}$ATPase activity through dissipation of plasma membrane potential induced by the weak acids [63]. It is known that uncharged weak-acids can difuse freely across plasmatic membrane. Due to a more neutral intracellular $\mathrm{pH}$, charged anions and protons are retained within cell, and cytoplasmic protons are expelled by membrane bound $\mathrm{H}^{+} \mathrm{ATPase}$
[63,64]. Beyond disrupting internal pH homeostasis, weak acids can also affect lipid organization and function of cellular membranes [63]. The data obtained regarding ATP synthase subunit beta expression showed a higher expression in mutants RAC-25 and RAC-21 at 15 and $24 \mathrm{~h}$ of cultivations in comparison to the wild strain; presenting statistically significant differences only at $15 \mathrm{~h}$ between RAC-25 and WT (Fig. 5). At the end of cultivation ( $48 \mathrm{~h}$ ), all the strains (mutants and WT) showed a decreased expression of this gene. In recent work, Mamata et al. applied adaptive laboratory evolution to improve Lactobacillus delbriecki FMI performance at low pH (4.5), and showed a 1.80-fold increase in lactic acid production compared to the parental strain. Moreover, the evolved strain exhibited a higher $\mathrm{H}^{+}$ATPase activity, as well as a higher $\mathrm{H}^{+}$ATPase gene expression compared to the parent strain [65]. Guan et al. performed comparative genomics and transcriptomics analysis in an acid-tolerant strain of Propionibacterium acidipropionic to understand the microbial response of cells to acid stress during fermentation. The results showed that genes involved in ATP synthesis were found to differ in copy numbers between the two strains (evolved and parental strain). Thus, they concluded that several transporters, membrane proteins, and the ATP synthase delta chain contributed to phenotype differences between the wild type strain and an acid-resistant mutant [66]. The result confirms our data, supporting that an up-regulation of both ATP synthases (beta and delta subunits) may contribute to the enhanced acid tolerance displayed by RAC-21 and RAC-25 mutants.

\subsection{Scanning electron microscopy (SEM)}

In the adaptive laboratory evolution strategy, we observed some cellular morphological changes during cultivations under routine light microscopy observation (data not shown). Therefore, we decided to investigate these changes in morphology using SEM. Images of three mutants (RAC-2, RAC-21, and RAC-25) and the wild type in the midexponential phase of cultivation ( $15 \mathrm{~h}$ ) were obtained by SEM (Fig. 6).

The images revealed the differences between wild type (Fig. 6A) and evolved strains (Fig. 6B-D). It is shown that the mutants were much more elongated (almost 2 twofold) in length in comparison to the wild 
A

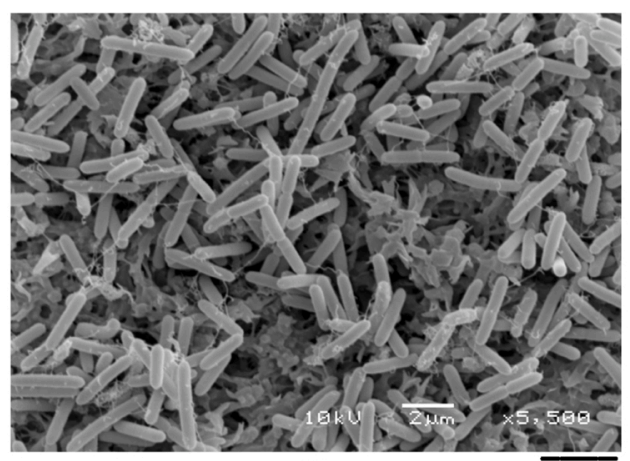

c

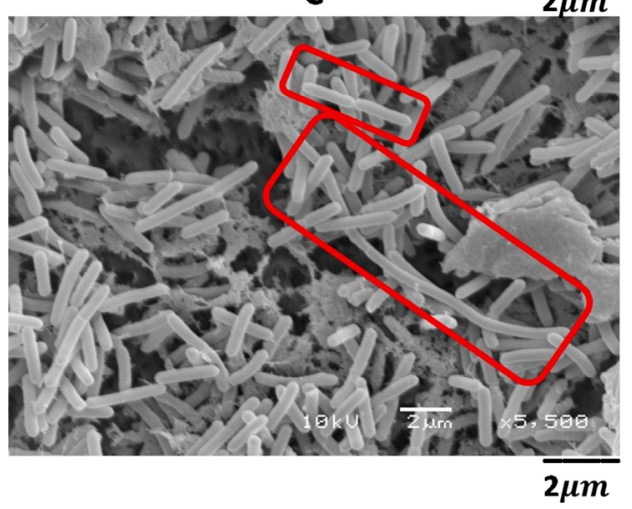

B

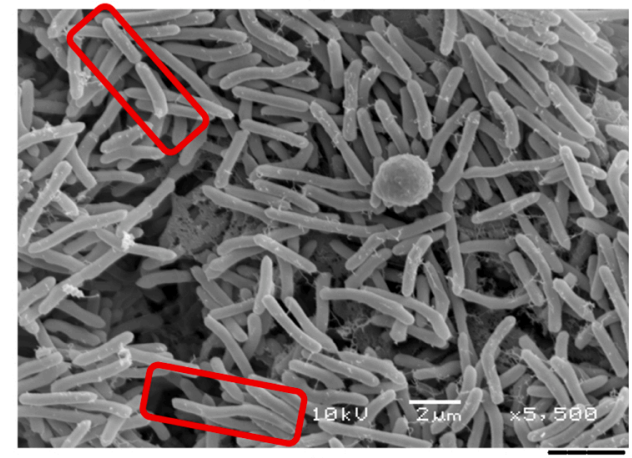

D

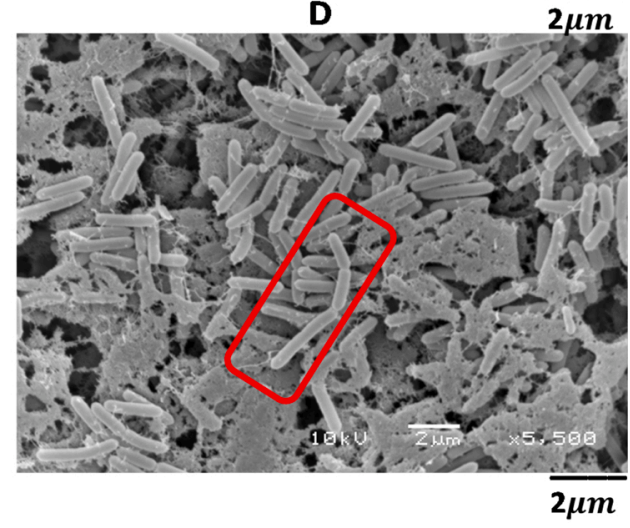

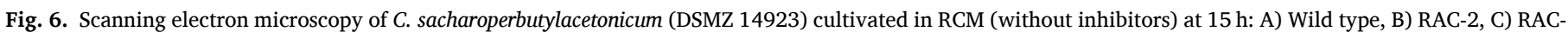

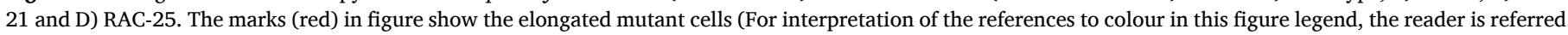
to the web version of this article).

type (control experiment). We believe that these changes can be related to the mutation found in sig $I$ and anti-sig $I$ which directly affect sigI expression, as previously observed in Fig. 5. Alterations in cell morphology have been described as a visible indicator of bacterial strategies to tackle different environmental stress conditions [67]. In recent work, Zhang et al. performed a comparative transcriptome analysis of a $C$. beijerinkii degenerated strain and the wild type 8052 strain. They found that morphological and physiological changes in the degenerated strain DG-8052 were related to disturbed expression of sigma factors; affecting aspects of sugar transport and metabolism, sporulation, chemotaxis and solventogenic pathways [68].

\section{Conclusions}

In this work, four robust strains of $C$. saccharoperbutylacetonicum able to withstand a high concentration of acetic acid and HMF were successfully obtained through ALE. The genome analysis indicated that a down-regulation of sigI can be directly involved in the improved tolerance of those strains. Moreover, the genes involved in membrane transport and metabolism of carbohydrates seem to be linked to a cellular strategy for adaptation to the challenging environment promoted by inhibitors. Our results bring important information about genes directly related to tolerance mechanism of cells, suggesting interesting targets for future metabolic engineering to obtain robust strains of $C$. saccharoperbutylacetonicum.

\section{CRediT authorship contribution statement}

Rafael F. Alves: Conceptualization, Investigation, Data curation, Methodology, Writing - original draft. Ana M. Zetty-Arenas: Investigation, Writing - review \& editing. Huseyin Demirci: Investigation, Writing - review \& editing. Oscar Dias: Investigation, Writing - review \& editing. Isabel Rocha: Supervision, Writing - review \& editing.
Thiago O. Basso: Conceptualization, Supervision, Writing - review \& editing. Sindelia Freitas: Conceptualization, Funding acquisition, Investigation, Project administration, Supervision, Writing - review \& editing.

\section{Declaration of Competing Interest}

The authors report no declarations of interest.

\section{Acknowledgements}

The authors would like to thank the Brazilian Center for Research in Energy and Materials (CNPEM) for providing access to the bioprocess facility of the Brazilian Biorenewables National Laboratory, and CNPq (400803/2013-5), FCT (UID/BIO/04469), BioTecNorte Operation (NORTE-01-0145-FEDER-000004) and Portuguese Biological Data Network" (ref. LISBOA-01-0145-FEDER-022231) for financial support.

\section{Appendix A. Supplementary data}

Supplementary material related to this article can be found, in the online version, at doi:https://doi.org/10.1016/j.procbio.2020.11.013.

\section{References}

[1] P. Dürre, Biobutanol: an attractive biofuel, Biotechnol. J. 2 (2007) 1525-1534, https://doi.org/10.1002/biot.200700168.

[2] S.Y. Lee, J.H. Park, S.H. Jang, L.K. Nielsen, J. Kim, K.S. Jung, Fermentative butanol production by clostridia, Biotechnol. Bioeng. 101 (2008) 209-228, https://doi.org/ 10.1002/bit.22003.

[3] H.G. Moon, Y. Jang, C. Cho, J. Lee, R. Binkley, S.Y. Lee, One Hundred Years of Clostridial Butanol Fermentation, 2016.

[4] Y. Jiang, J. Liu, W. Jiang, Y. Yang, S. Yang, Current status and prospects of industrial bio-production of n-butanol in China, Biotechnol. Adv. 33 (2015) 1493-1501, https://doi.org/10.1016/j.biotechadv.2014.10.007. 
[5] S. Maiti, S.J. Sarma, S.K. Brar, Y. Le Bihan, P. Drogui, G. Buelna, M. Verma, Agroindustrial wastes as feedstock for sustainable bio-production of butanol by Clostridium beijerinckii, Food Bioprod. Process. 98 (2016) 217-226, https://doi. org/10.1016/j.fbp.2016.01.002.

[6] M. Rastogi, S. Shrivastava, Recent advances in second generation bioethanol production: an insight to pretreatment, saccharification and fermentation processes, Renew. Sustain. Energy Rev. 80 (2017) 330-340, https://doi.org/ 10.1016/j.rser.2017.05.225.

[7] C.L. Cheng, P.Y. Che, B.Y. Chen, W.J. Lee, C.Y. Lin, J.S. Chang, Biobutanol production from agricultural waste by an acclimated mixed bacterial microflora, Appl. Energy 100 (2012) 3-9, https://doi.org/10.1016/j.apenergy.2012.05.042.

[8] S. Alfenore, C. Molina-Jouve, Current status and future prospects of conversion of lignocellulosic resources to biofuels using yeasts and bacteria, Process Biochem. 51 (2016) 1747-1756, https://doi.org/10.1016/j.procbio.2016.07.028.

[9] M. Galbe, G. Zacchi, Pretreatment: The key to efficient utilization of lignocellulosic materials, Biomass\& Bioenergy 46 (2012) 70-78, https://doi.org/10.1016/j. biombioe.2012.03.026.

[10] F.M. Gírio, C. Fonseca, F. Carvalheiro, L.C. Duarte, S. Marques, R. Bogel-Łukasik, Hemicelluloses for fuel ethanol: a review, Bioresour. Technol. 101 (2010) 4775-4800, https://doi.org/10.1016/j.biortech.2010.01.088.

[11] N.R. Baral, A. Shah, Microbial inhibitors : formation and effects on acetonebutanol-ethanol fermentation of lignocellulosic biomass, Appl. Microbiol. Biotechnol. (2014) 9151-9172, https://doi.org/10.1007/s00253-014-6106-8.

[12] N. Abdehagh, F.H. Tezel, J. Thibault, Separation techniques in butanol production: challenges and developments, Biomass\&Bioenergy 60 (2014) 222-246, https:// doi.org/10.1016/j.biombioe.2013.10.003.

[13] O. Ibraheem, B.K. Ndimba, Molecular adaptation mechanisms employed by ethanologenic bacteria in response to lignocellulose-derived inhibitory compounds, Int. J. Biol. Sci. 9 (2013) 598-612, https://doi.org/10.7150/ijbs.6091.

[14] D. Yao, S. Dong, P. Wang, T. Chen, J. Wang, Z.-B. Yue, Y. Wang, Robustness of Clostridium saccharoperbutylacetonicum for Acetone-Butanol-Ethanol production: effects of lignocellulosic sugars and inhibitors, Fuel 208 (2017), https://doi.org/ 10.1016/j.fuel.2017.07.004004 (under-revision).

[15] A. Cavka, L.J. Jönsson, Detoxification of lignocellulosic hydrolysates using sodium borohydride, Bioresour. Technol. 136 (2013) 368-376, https://doi.org/10.1016/j. biortech.2013.03.014.

[16] D. Ludwig, M. Amann, T. Hirth, S. Rupp, S. Zibek, Development and optimization of single and combined detoxification processes to improve the fermentability of lignocellulose hydrolyzates, Bioresour. Technol. 133 (2013) 455-461, https://doi. org/10.1016/j.biortech.2013.01.053.

[17] R. Tramontina, L.B. Brenelli, A. Sousa, R. Alves, A.M. Zetty Arenas, V. M. Nascimento, S.C. Rabelo, S. Freitas, R. Ruller, F.M. Squina, Designing a cocktail containing redox enzymes to improve hemicellulosic hydrolysate fermentability by microorganisms, Enzyme Microb. Technol. 135 (2020), https://doi.org/10.1016/j. enzmictec.2019.109490.

[18] K.M. Lee, K. Kim, O. Choi, H.M. Woo, Y. Kim, S.O. Han, B. Sang, Y. Um, In situ detoxification of lignocellulosic hydrolysate using a surfactant for butyric acid production by Clostridium tyrobutyricum ATCC 25755, Process Biochem. (2015), https://doi.org/10.1016/j.procbio.2015.01.020.

[19] L.J. Jönsson, C. Martín, Pretreatment of lignocellulose: formation of inhibitory byproducts and strategies for minimizing their effects, Bioresour. Technol. 199 (2016) 103-112, https://doi.org/10.1016/j.biortech.2015.10.009.

[20] M. Dragosits, D. Mattanovich, Adaptive laboratory evolution - principles and applications for biotechnology, Microb. Cell Fact. 12 (2013) 64, https://doi.org/ 10.1186/1475-2859-12-64

[21] T. Guo, A.Y. He, T.F. Du, D.W. Zhu, D.F. Liang, M. Jiang, P. Wei, P.K. Ouyang, Butanol production from hemicellulosic hydrolysate of corn fiber by a Clostridium beijerinckii mutant with high inhibitor-tolerance, Bioresour. Technol. 135 (2013) 379-385, https://doi.org/10.1016/j.biortech.2012.08.029.

[22] X. Wang, I. Khushk, Y. Xiao, Q. Gao, J. Bao, Tolerance improvement of Corynebacterium glutamicum on lignocellulose derived inhibitors by adaptive evolution, Appl. Microbiol. Biotechnol. 102 (2018) 377-388, https://doi.org/ 10.1007/s00253-017-8627-4.

[23] A.M. Zetty-Arenas, R.F. Alves, C.A.F. Portela, A.P. Mariano, T.O. Basso, L.P. Tovar, R. Maciel Filho, S. Freitas, Towards enhanced n-butanol production from sugarcane bagasse hemicellulosic hydrolysate: strain screening, and the effects of sugar concentration and butanol tolerance, Biomass Bioenergy 126 (2019) 190-198, https://doi.org/10.1016/j.biombioe.2019.05.011.

[24] B.S. Santucci, P. Maziero, S.C. Rabelo, A.A.S. Curvelo, M.T.B. Pimenta, Autohydrolysis of hemicelluloses from sugarcane bagasse during hydrothermal pretreatment: a kinetic assessment, Bioenergy Res. 8 (2015) 1778-1787, https:// doi.org/10.1007/s12155-015-9632-z.

[25] D. González-Ramos, A.R. Gorter De Vries, S.S. Grijseels, M.C. Van Berkum, S. Swinnen, M. Van Den Broek, E. Nevoigt, J.M.G. Daran, J.T. Pronk, A.J.A. Van Maris, A new laboratory evolution approach to select for constitutive acetic acid tolerance in Saccharomyces cerevisiae and identification of causal mutations, Biotechnol. Biofuels 9 (2016) 1-18, https://doi.org/10.1186/s13068-016-0583-1.

[26] A.M. Bolger, M. Lohse, B. Usadel, Genome analysis Trimmomatic : a flexible trimmer for Illumina sequence data, Bioinformatics (2014) 1-7, https://doi.org/ 10.1093/bioinformatics/btu170.

[27] H. Li, R. Durbin, Fast and accurate long-read alignment with Burrows - wheeler transform, Bioinformatics 26 (2010) 589-595, https://doi.org/10.1093/ bioinformatics/btp698.

[28] H. Li, B. Handsaker, A. Wysoker, T. Fennell, J. Ruan, N. Homer, G. Marth, G. Abecasis, R. Durbin, G.P. Data, T. Sam, The sequence alignment / map format and SAMtools, Bioinformatics 25 (2009) 2078-2079, https://doi.org/10.1093/ bioinformatics/btp352.

[29] D.C. Koboldt, Q. Zhang, D.E. Larson, D.C. Koboldt, Q. Zhang, D.E. Larson, D. Shen, M.D. Mclellan, L. Lin, C.A. Miller, E.R. Mardis, L. Ding, R.K. Wilson, VarScan 2 : somatic mutation and copy number alteration discovery in cancer by exome sequencing VarScan 2 : somatic mutation and copy number alteration discovery in cancer by exome sequencing, Genome Res. (2012) 568-576, https://doi.org/ 10.1101/gr.129684.111.

[30] P. Cingolani, A. Platts, L.L. Wang, M. Coon, T. Nguyen, L. Wang, S.J. Land, X. Lu, D. M. Ruden, A program for annotating and predicting the effects of single nucleotide polymorphisms, SnpEff: SNPs in the genome of Drosophila melanogaster strain w1118; iso-2; iso-3, Fly (Austin) 6 (2012) 80-92, https://doi.org/10.4161/ fly. 19695.

[31] T. Seemann, Genome analysis Prokka : rapid prokaryotic genome annotation, Bioinformatics 2 (2014) 1-2, https://doi.org/10.1093/bioinformatics/btu153.

[32] C.F. Interests, Integrative genomics viewer, Nat. Biotechnol. 29 (2011) 24-26, https://doi.org/10.1038/nbt0111-24.

[33] T. Rausch, T. Zichner, A. Schlattl, A.M. Stütz, V. Benes, J.O. Korbel, DELLY : structural variant discovery by integrated paired-end and split-read analysis, Bioinformatics 28 (2012) 333-339, https://doi.org/10.1093/bioinformatics/ bts378.

[34] B. Langmead, S.L. Salzberg, Fast gapped-read alignment with Bowtie, Nat. Methods 2 (9) (2012) 357-360, https://doi.org/10.1038/nmeth.1923.

[35] G.P. Borin, C.C. Sanchez, E.S. de Santana, G.K. Zanini, R.A.C. dos Santos, A. de Oliveira Pontes, A.T. de Souza, R.M.M.T.S. Dal'Mas, D.M. Riaño-Pachón, G. H. Goldman, J.V. de C. Oliveira, Comparative transcriptome analysis reveals different strategies for degradation of steam-exploded sugarcane bagasse by Aspergillus niger and Trichoderma reesei, BMC Genomics 18 (2017) 501, https:// doi.org/10.1186/s12864-017-3857-5.

[36] M.C.B. Grassi, M.F. Carazzolle, B.T. Nakagawa, A. Ferrari, S. Nagamatsu, C. R. Santos, M.T. Murakami, R.A.S. Pirolla, G.A.G. Pereira, New contributions for industrial n-butanol fermentation: an optimized Clostridium strain and the use of xylooligosaccharides as a fermentation additive, Biomass Bioenergy 119 (2018) 304-313, https://doi.org/10.1016/j.biombioe.2018.09.012.

[37] Y. Jang, Y. Lee, J. Lee, H. Park, A. Im, M. Eom, J. Lee, S. Lee, Enhanced butanol production obtained by reinforcing the direct butanol-forming route in Clostridium acetobutylicum, mBio 3 (2012) 1-9, https://doi.org/10.1128/mBio.00314-12. Invited.

[38] H. Shinto, Y. Tashiro, G. Kobayashi, T. Sekiguchi, T. Hanai, Y. Kuriya, M. Okamoto, K. Sonomoto, Kinetic study of substrate dependency for higher butanol production in acetone-butanol-ethanol fermentation, Process Biochem. 43 (2008) 1452-1461, https://doi.org/10.1016/j.procbio.2008.06.003.

[39] Y. Jin, Y. Fang, M. Huang, J. Sun, Y. Huang, X. Gao, R. Li, K. He, H. Zhao, Combination of RNA sequencing and metabolite data to elucidate improved toxic compound tolerance and butanol fermentation of Clostridium acetobutylicum from wheat straw hydrolysate by supplying sodium sulfide, Bioresour. Technol. 198 (2015) 77-86, https://doi.org/10.1016/j.biortech.2015.08.139.

[40] A. Kashiwagi, I. Urabe, K. Kaneko, T. Yomo, Adaptive response of a gene network to environmental changes by fitness-induced attractor selection, PLoS One 1 (2006), https://doi.org/10.1371/journal.pone.0000049.

[41] M.S. Paget, Bacterial sigma factors and anti-sigma factors: structure, function and distribution, Biomolecules 5 (2015) 1245-1265, https://doi.org/10.3390/ biom5031245.

[42] U. Zuber, K. Drzewiecki, M. Hecker, Putative sigma factor SigI (YkoZ) of Bacillus subtilis is induced by heat shock putative sigma factor SigI (YkoZ) of Bacillus subtilis is induced by heat shock, J. Bacteriol. 183 (2001) 1472-1475, https://doi. org/10.1128/JB.183.4.1472.

[43] T.Y. Liu, S.H. Chu, Y.N. Hu, J.J. Wang, G.C. Shaw, Genetic evidence that multiple proteases are involved in modulation of heat-induced activation of the sigma factor SigI in Bacillus subtilis, FEMS Microbiol. Lett. 364 (2017) 1-7, https://doi.org/ 10.1093/femsle/fnx054.

[44] K. Asai, T. Ootsuji, K. Obata, T. Matsumoto, Y. Fujita, Y. Sadaie, Regulatory role of RsgI in sigI expression in Bacillus subtilis, Microbiology 153 (2007) 92-101, https://doi.org/10.1099/mic.0.29239-0.

[45] C.L. Tseng, J.T. Chen, J.H. Lin, W.Z. Huang, G.C. Shaw, Genetic evidence for involvement of the alternative sigma factor SigI in controlling expression of the cell wall hydrolase gene lytE and contribution of LytE to heat survival of Bacillus subtilis, Arch. Microbiol. 193 (2011) 677-685, https://doi.org/10.1007/s00203011-0710-0.

[46] F. Zhang, X. Qian, H. Si, G. Xu, R. Han, Y. Ni, Significantly improved solvent tolerance of Escherichia coli by global transcription machinery engineering, Microb. Cell Fact. 14 (2015) 1-11, https://doi.org/10.1186/s12934-015-0368-4.

[47] L. Notley-mcrobb, T. King, T. Ferenci, rpoS mutations and loss of general stress resistance in Escherichia coli populations as a consequence of conflict between competing stress responses rpoS mutations and loss of general stress resistance in Escherichia coli populations as a consequence of C, J. Bacteriol. 184 (2002) 806-811, https://doi.org/10.1128/JB.184.3.806.

[48] A. Mitra, Sigma Factor N : a Novel Regulator of Acid Resistance and Locus of Enterocyte Effacement in Escherichia coli O157 : H7, Univ. South Florida Sch. Commons., 2014.

[49] E. Dahlsten, D. Kirk, M. Lindström, H. Korkeala, Alternative sigma factor sigK has a role in stress tolerance of group I Clostridium botulinum strain ATCC 3502, Appl. Environ. Microbiol. 79 (2013) 3867-3869, https://doi.org/10.1128/AEM.0403612. 
[50] L. Zhang, S.A. Leyn, Y. Gu, W. Jiang, D.A. Rodionov, C. Yang, Ribulokinase and transcriptional regulation of arabinose metabolism in clostridium acetobutylicum, J. Bacteriol. 194 (2012) 1055-1064, https://doi.org/10.1128/JB.06241-11.

[51] I.S. Franco, J. Mota, M. Soares, I. De Sa, Functional domains of the Bacillus subtilis transcription factor AraR and identification of amino acids important for nucleoprotein complex assembly and effector binding, J. Bacteriol. 188 (2006) 3024-3036, https://doi.org/10.1128/JB.188.8.3024.

[52] T.C. Ezeji, S. Liu, N. Qureshi, Mixed sugar fermentation by clostridia and metabolic engineering for butanol production. Biorefineries Integr. Biochem. Process. Liq. Biofuels, 2014, pp. 191-204, https://doi.org/10.1016/B978-0-444-594983.00009-9.

[53] S. Hu, H. Zheng, Y. Gu, J. Zhao, W. Zhang, Y. Yang, S. Wang, G. Zhao, S. Yang, W. Jiang, Comparative genomic and transcriptomic analysis revealed genetic characteristics related to solvent formation and xylose utilization in Clostridium acetobutylicum EA 2018, BMC Genomics 12 (2011) 93, https://doi.org/10.1186/ 1471-2164-12-93.

[54] H. Xiao, Z. Li, Y. Jiang, Y. Yang, W. Jiang, Y. Gu, S. Yang, Metabolic engineering of d-xylose pathway in Clostridium beijerinckii to optimize solvent production from xylose mother liquid, Metab. Eng. 14 (2012) 569-578, https://doi.org/10.1016/j. ymben.2012.05.003.

[55] M. Xiao, X. Zhu, H. Xu, J. Tang, R. Liu, C. Bi, F. Fan, X. Zhang, A novel point mutation in RpoB improves osmotolerance and succinic acid production in Escherichia coli, BMC Biotechnol. 17 (2017) 1-11, https://doi.org/10.1186/ s12896-017-0337-6.

[56] W.J. Mitchell, Sugar uptake by the solventogenic clostridia, World J. Microbiol. Biotechnol. 32 (2016) 1-10, https://doi.org/10.1007/s11274-015-1981-4.

[57] J.J. Minty, A.A. Lesnefsky, F. Lin, Y. Chen, T.A. Zaroff, A.B. Veloso, B. Xie, C. A. Mcconnell, R.J. Ward, D.R. Schwartz, J. Rouillard, Y. Gao, E. Gulari, X.N. Lin, Evolution combined with genomic study elucidates genetic bases of isobutanol tolerance in Escherichia coli, Microb. Cell Fact. 10 (2011) 18, https://doi.org/ 10.1186/1475-2859-10-18.

[58] J.T. Riordan, J.A. Tietjen, C.W. Walsh, J.E. Gustafson, T.S. Whittam, Inactivation of alternative sigma factor 54 (RpoN) leads to increased acid resistance, and alters locus of enterocyte effacement (LEE) expression in Escherichia coli O157:H7, Microbiology 156 (2010) 719-730, https://doi.org/10.1099/mic.0.032631-0.
[59] X. Liang, L. Zhang, S.K. Natarajan, D.F. Becker, Proline mechanisms of stress survival, Antioxid. Redox Signal. (2013), https://doi.org/10.1089/ars.2012.5074.

[60] Z. Liao, X. Guo, J. Hu, Y. Suo, H. Fu, J. Wang, The significance of proline on lignocellulose-derived inhibitors tolerance in Clostridium acetobutylicum ATCC 824, Bioresour. Technol. 272 (2019) 561-569, https://doi.org/10.1016/j. biortech.2018.10.038.

[61] C.A. Tomas, N.E. Welker, E.T. Papoutsakis, Overexpression of groESL in Clostridium acetobutylicum results in increased solvent production and tolerance, prolonged metabolism, and changes in the cell's transcriptional program, Appl. Environ. Microbiol. 69 (2003) 4951-4965, https://doi.org/10.1128/ AEM.69.8.4951-4965.2003.

[62] S. Lee, J.H. Lee, R.J. Mitchell, Analysis of Clostridium beijerinckii NCIMB 8052' s transcriptional response to ferulic acid and its application to enhance the strain tolerance, Biotechnol. Biofuels (2015) 1-14, https://doi.org/10.1186/s13068-0150252-9.

[63] J.K. Ndukwe, G.O. Aliyu, C.O. Onwosi, K.O. Chukwu, F.N. Ezugworie, Mechanisms of weak acid-induced stress tolerance in yeasts : prospects for improved bioethanol production from lignocellulosic biomass, Process Biochem. (2019) 0-1, https:// doi.org/10.1016/j.procbio.2019.11.009.

[64] R.J. Lambert, M. Stratford, Weak-Acid Preservatives : Modelling Microbial Inhibition and Response, 1999, pp. 157-164.

[65] M. Singhvi, T. Zendo, D. Gokhale, K. Sonomoto, Greener L-lactic acid production through in situ extractive fermentation by an acid-tolerant Lactobacillus strain, Appl. Microbiol. Biotechnol. 102 (2018) 6425-6435, https://doi.org/10.1007/ s00253-018-9084-4.

[66] N. Guan, B. Du, J. Li, H.D. Shin, R.R. Chen, G. Du, J. Chen, L. Liu, Comparative genomics and transcriptomics analysis-guided metabolic engineering of Propionibacterium acidipropionici for improved propionic acid production, Biotechnol. Bioeng. 115 (2018) 483-494, https://doi.org/10.1002/bit.26478.

[67] S.S. Justice, D.A. Hunstad, L. Cegelski, S.J. Hultgren, Morphological plasticity as a bacterial survival strategy, Nat. Rev. Microbiol. 6 (2008) 162-168, https://doi. org/10.1038/nrmicro1820.

[68] Y. Zhang, S. Jiao, J. Lv, R. Du, X. Yan, C. Wan, R. Zhang, B. Han, Sigma factor regulated cellular response in a non-solvent producing Clostridium beijerinckii degenerated strain: A comparative transcriptome analysis, Front. Microbiol. 8 (2017) 1-12, https://doi.org/10.3389/fmicb.2017.00023. 